Research Article

\title{
A comparative study of intrathecal ropivacaine with fentanyl and L-bupivacaine with fentanyl in lower abdominal and lower limb surgeries
}

\author{
Prem Swarup Vampugalla ${ }^{1}$, Venkata Ramana Vundi ${ }^{2}$, Kamala Subhashini Perumallapalli2*, \\ Ch. Vinod Kumar ${ }^{1}$, Chandrakala Kambar ${ }^{2}$, P. Mallika Mahalakshmi ${ }^{3}$, Raja Sulochana Pisipati²
}

\begin{abstract}
${ }^{1}$ Department of Anaesthesia, Dr. Pinnamaneni Siddhartha Institute of Medical Sciences and Research Foundation, Chinnaoutpalli, Andhra Pradesh, India, ${ }^{2}$ Department of Pharmacology, Siddhartha Medical College, Vijayawada, Andhra Pradesh, India, ${ }^{3}$ Department of Oral Medicine and Radiology, Mamatha Medical College, Khammam, Telangana, India
\end{abstract}

Received: 29 September 2015 Revised: 01 October 2015 Accepted: 21 October 2015

\section{*Correspondence to:}

Dr. Kamala Subhashini Perumallapalli, Email: kamala.subha@gmail. com

Copyright: (C) the author(s), publisher and licensee Medip Academy. This is an openaccess article distributed under the terms of the Creative Commons Attribution NonCommercial License, which permits unrestricted noncommercial use, distribution, and reproduction in any medium, provided the original work is properly cited.

\begin{abstract}
Background: Subarachnoid block (SAB) is the anesthesia of choice and is the gold standard for lower abdominal and lower limb surgeries. SAB, a popular and common anesthetic procedure practiced worldwide. Today heavy bupivacaine, $0.5 \%$ is most commonly used for spinal anesthesia. Levo-bupivacaine, new long-acting local anesthetic, has a pharmacological activity very similar to that of racemic bupivacaine. Due to lesser cardiovascular side-effects and central nervous system toxicity, use of levo-bupivacaine, a pure S (-) enantiomer of bupivacaine has progressively increased. Ropivacaine has a less systemic toxicity, especially cardio toxic profile than both racemic and levo-bupivacaine. Though less potent, even 50\% higher dose is still less toxic than bupivacaine. So, intrathecal ropivacaine may prove useful than that of bupivacaine or levo-bupivacaine when anesthesia of a similar quality and shorter duration is desired. Methods: This study was conducted in 60 adult patients aged between 18 and 60 years, who underwent elective lower abdominal and lower limb surgeries under spinal anesthesia. They were distributed in two groups. Group R: 30 patients were given injection ropivacaine $3 \mathrm{ml}(0.75 \%)+$ injection fentanyl $0.5 \mathrm{ml}(25 \mu \mathrm{g})$. Group L: 30 patients were given injection L-bupivacaine $3 \mathrm{ml}(0.5 \%)+$ injection fentanyl $0.5 \mathrm{ml}$ $(25 \mu \mathrm{g})$. Hemodynamic parameters such as pulse rate, blood pressure, and respiratory rate, sensory and motor blockade were assessed at $0,5,10,15,30,45,60,90$, and 120 mins following the block. Thereafter, observation was continued at 30 mins intervals until the motor block regressed completely as defined by modified Bromage score. Time of two segment regression, duration of complete and effective analgesia, and time to first analgesic dose, side effects, and complications were studied.

Results: Statistical analysis was done using SPSS software 16.0. Data obtained is tabulated in the excel sheet and analyzed. Chi-square test for proportion and t-test for quantitative data were done. Block characteristics were compared using Mann-Whitney U-test. Both the groups were comparable with respect to age, sex, height, weight, body mass index, level of SAB, American Society of Anesthesiologist score ( $p>0.05)$. The mean time for onset of sensory block with $\mathrm{p}=0.49$ which was clinically and statistically not significant for both groups. The mean time for onset of motor block (Bromage 3 ) with $\mathrm{p}=0.16$ was clinically and statistically not significant. The time taken for two segment regression of sensory block was $\mathrm{p}=0.22$ statistically not significant. There was no clinical or statistical significance in the incidence of side effects in both groups. Conclusion: This study revealed that the intrathecal ropivacaine with fentanyl provided adequate anesthesia for lower abdominal and lower limb surgeries. Ropivacaine achieved a shorter duration of sensory and motor blockade, and a lesser degree of motor blockade when compared to L-bupivacaine. Thus, ropivacaine was justified for short duration ambulatory surgeries of lower abdominal and lower limb surgeries. Furthermore, fentanyl as an adjuvant to both ropivacaine and L-bupivacaine enhanced the duration of the sensory block. Hence, ropivacaine with fentanyl in spinal anesthesia for lower abdominal and lower limb surgeries is a better alternative compared to L-bupivacaine with fentanyl favoring day care ambulatory surgeries.
\end{abstract}

Keywords: Day care ambulatory surgery, Fentanyl, Intrathecal, Levo-bupivacaine, Lower abdominal, Lower limb surgery, Ropivacaine 


\section{INTRODUCTION}

Subarachnoid block (SAB), a popular and common anesthetic procedure practiced worldwide and was first performed by August Bier more than a century ago by injecting cocaine into cerebrospinal fluid (CSF) of a patient. $\mathrm{SAB}$ is the anesthesia of choice and is the gold standard for lower abdominal and lower limb surgeries.

\section{Ropivacaine}

It is a new long-acting local anesthetic drug belonging to the amino amide group, a propyl derivatives of pipecoloxylidides.

\section{Mechanism of action}

Ropivacaine reversibly interferes with the entry of sodium in the nerve cell membranes, leading to decreased permeability to sodium. It blocks generation and conductance of nerve impulses. Blockade of $A \alpha$ and $A \beta$ is slow and hence produces lesser motor blockade than bupivacaine.

\section{Pharmacokinetics}

After intravascular infusion, ropivacaine achieves a steady state of distribution of $41 \pm 7$ L. 94\% protein bound, extensively metabolized in the liver and mainly excreted by the kidney. It readily crosses the placenta.

\section{Adverse effects}

Central nervous system (CNS) toxicity begins with $0.6 \mu \mathrm{g} / \mathrm{ml}$. This can occur if prolonged blocks were given leading to local neural injury. Other side-effects include pain at the injection site, vasovagal reaction, syncope, postural hypotension, non-specific electrocardiogram (ECG) changes, fecal incontinence, tenesmus, nausea, vomiting, tremors, Horner's syndrome, dyskinesia, neuropathy, vertigo, convulsion, coma, jaundice, and hypomagnesemia.

\section{Drug interactions}

Ropivacaine should be used with caution in patients receiving other local anesthetics or agents structurally related to amide type, as these are additives. Fluvoxamine which belongs to selective serotonin reuptake inhibitor group, is a strong inhibitor of CYP450 1A2, can interact with ropivacaine leading to its increased plasma levels.

\section{Advantages over other local anesthetics}

Ropivacaine produces a more differential blockade allowing better separation between sensory and motor block and hence a better choice for use in labor analgesia and post- operative pain relief. When compared to bupivacaine, it produces lesser motor blockade of shorter duration and hence permitting earlier mobilization and discharge.

Systemic toxicity especially cardio toxicity is lesser with racemic and levo-bupivacaine. Though $40-50 \%$ less potent than bupivacaine, ropivacaine in an equipotency ratio of 1.5:1 produces results in a similar clinical profile with good preservation of motor function. ${ }^{1}$

\section{Levo-bupivacaine}

Bupivacaine is widely used local anesthetic in regional anesthesia. Chemically it is an amino-amide local anesthetic belonging to the family of n-alkyl substitute pipecoloxylidide. It is available as a racemic mixture (50:50) of its two enantiomers, levo-bupivacaine, S (-) isomer and dextro-bupivacaine, $\mathrm{R}(+)$ isomer. Severe CNS and cardiovascular system adverse effects were reported in the literature after intravascular injection or intravenous (i.v.) regional anesthesia with $\mathrm{R}(+)$ isomer of bupivacaine. The levorotatory isomers were shown to have a safer pharmacological profile with lesser cardiac and neurotoxic adverse effects. The decreased toxicity of levo-bupivacaine is attributed to its faster protein binding rate. ${ }^{2}$

\section{Mechanism of action}

Levo-bupivacaine specifically binds to the intracellular portion of sodium channels and blocks sodium influx into nerve cells, which prevents depolarization. It blocks nerve conduction in sensory and motor nerves.

\section{Pharmacokinetics}

After epidural administration of levo-bupivacaine, the absorption is biphasic, with rapid absorption of a small quantity of drug into the circulation and slower absorption of the remainder of the drug. The epidural absorption gets affected by age, therefore in the elderly patients, a lower dose is recommended. The volume of distribution is estimated at $66.91 \pm 18.23 \mathrm{~L}$. The half-life is $3.3 \mathrm{hrs}$. The rate of clearance is $39.06 \pm 13.29 \mathrm{~L} / \mathrm{hrs}$. Alpha1-glycoprotein is the main binding site for levo-bupivacaine. Protein binding is more $(97 \%)$ than that of racemic bupivacaine $(95 \%)$. Less than $3 \%$ of the drug circulates free in plasma and may be the cause for unwanted toxic effects. Extensively metabolized by CYP3A4 and CYP1A2 and excreted in the urine and feces.

\section{Adverse effects}

Levo-bupivacaine produces the same adverse effects as seen with racemic bupivacaine and other local anesthetics. The most common is hypotension (31\%) followed by nausea $(21 \%)$, vomiting $(14 \%)$, headache $(9 \%)$, procedural pain 
(8\%), and dizziness (6\%). The cardiac toxicity, neurological injury after peripheral nerve block and unwanted CNS effects, may be lesser than bupivacaine. Allergic reactions such as urticaria are rare. Levo-bupivacaine has a safety margin of 1.3, which means toxic effects are not seen until the concentration rises by $30 \%$. The concentration necessary to produce cardiac and neurotoxicity is higher for levobupivacaine than for racemic bupivacaine.

\section{Clinical utility}

The low cardiovascular and neurological toxicity of levobupivacaine has led to its application as a local anesthetic in a wide variety of specialist applications such as subarachnoid block, epidural anesthesia and analgesia, brachial plexus blocks, peripheral nerve blocks, ocular blocks, and local infiltration. It is also being used for intraoperative anesthesia, labor analgesia, post-operative pain, as well as management of acute and chronic pain.

\section{$S A B$}

Levo-bupivacaine is an interesting alternative to bupivacaine for spinal anesthesia. Levo-bupivacaine produces SAB with similar sensory and motor characteristics and recovery like bupivacaine, the regression of motor block occurs earlier with levo-bupivacaine and ropivacaine as compared with bupivacaine. Intrathecal administration of $15 \mathrm{mg}$ of levobupivacaine provides an adequate sensory and motor block lasting for approximately $6.5 \mathrm{hrs}$. Smaller doses of 5-10 mg can be used in day care surgeries. At low concentrations, levo-bupivacaine produces a differential neuraxial block with preservation of motor function, which may be favorable for ambulatory surgery. Minimum effective local anesthetic dose of levo-bupivacaine as recommended by an up-anddown sequential design study is $11.7 \mathrm{mg}$. The literary evidence has established that addition of opioids provides a dose sparing effect of levo-bupivacaine, with improved quality of the block and less hemodynamic variations during peri-operative period.

A potency hierarchy of intrathecal bupivacaine $<$ levobupivacaine $<$ ropivacaine in cesarean section patients has been confirmed in clinical studies.

\section{Fentanyl}

Fentanyl citrate is a synthetic phenylpiperidine opioid agonist that is structurally related to meperidine. As an analgesic, it is 75-125 times more potent than morphine. Fentanyl is primarily a $\mathrm{Mu}$ receptor agonist at the supraspinal site with an analgesic potency greater than morphine, pethidine, and alfentanil.

Fentanyl decreases in heart rate (HR) and fall in blood pressure (BP) are seen. It also slows A.V conduction, prolongs $\mathrm{R}-\mathrm{R}$ interval. There is a dose-related depression of breathing. Resting minute volume, tidal volume, and respiratory rate are decreased. The ventilator responses to hypercarbia and hypoxia are blunted. It produces no change or a modest reduction in cerebral blood flow and cerebral metabolism and oxygen consumption. Intestinal motility is decreased, and constipation can be the problem. It can increase the tone of the sphincter of Oddi and produce increased pressure in biliary ducts.

Fentanyl is both potent and safe and has a therapeutic index of 323 which is much greater than that of morphine - 69 and pethidine - 4.8 .

\section{Intrathecal actions}

Intrathecal administration produces selective spinal analgesia by acting on opioid receptors at substantia gelatinosa of dorsal horn of spinal cord. The major advantage of selective blockade of pain lies in the absence of sympathetic blockade and postural hypotension potentially allowing early ambulation of the patient and avoidance of cardiovascular collapse or convulsions, which are a major complication of the spinal anesthetic blockade.

Intrathecal dose: $10-25 \mu \mathrm{g}$, onset is 5 mins, Duration of action: 2-6 hrs.

\section{Potency}

Fentanyl is 100 times more potent in terms of dose than morphine when administered i.v. but is only 4 times more potent when administered intrathecal. It is a less hydrophilic opioid and has little rostral spread cause least respiratory depression when compared to morphine, which has greater rostral CSF spread.

Side effects of intrathecal fentanyl: pruritus, nausea and vomiting, urinary retention, respiratory depression, mental status changes, CNS excitation, neonatal morbidity, sexual dysfunction, ocular dysfunction, cardiac dysrhythmia, neurotoxicity, and anaphylactic reactions.

The addition of lipophilic opioids such as sufentanil and fentanyl improve and prolong intraoperative analgesia and reduce the amount of local anesthetic required to perform a sufficient dermatome spread and block intensity. This reduction in local anesthetic requirements reduces the intensity and duration of motor blockade and allows patients to ambulate faster. ${ }^{3}$

\section{Aims and objectives}

This study conducted in 60 adult patients aged between 18 and 60 years undergoing elective lower abdominal and lower limb surgeries under spinal anesthesia in Dr. Pinnamaneni Siddhartha Institute of Medical Sciences and Research Foundation, Chinaoutpalli, Andhra Pradesh, India. 
Group R: 30 patients were given injection ropivacaine + injection fentanyl.

Group L: 30 patients were given injection L-bupivacaine + injection fentanyl.

\section{Objectives of the study}

i. Onset and duration of sensory blockade

ii. Onset and duration of motor blockade

iii. Time of two segment regression

iv. Duration of complete and effective analgesia, time to first analgesic dose

v. Hemodynamic changes such as pulse rate, BP, and respiratory rate

vi. Side effects and complications.

\section{METHODS}

This is a prospective, comparative, interventional, singleblind study was conducted on 60 patients undergoing various lower abdominal and lower limb surgeries under $\mathrm{SAB}$ at Dr. Pinnamaneni Siddhartha Institute of Medical Sciences and Research Foundation, Chinnaoutpalli, between the months of May 2012 and October 2014. This study was conducted over a period of 30-month. Approval of the Institutional Ethics Committee was taken. A written informed consent in the local language was taken from every patient.

\section{Inclusion criteria}

i. Adult patients aged between 18 and 60 years of both sexes.

ii. Patients belonging to American Society of Anesthesiologist (ASA)

- Grade I: Without co-morbid condition

- Grade II: Controlled co-morbid conditions

\section{Exclusion criteria}

i. Emergency surgeries

ii. H/O hypersensitive reactions to local anesthetics

iii. Medical complications such as anemia, heart disease, severe hypovolemia, shock, septicemia, and hypertension

iv. Patients on anticoagulant therapy and $\mathrm{H} / \mathrm{O}$ coagulation disorders

v. Local infection at the site of proposed for puncture for spinal anesthesia

vi. Extremes of age group.

\section{Pre-anesthetic examination and preparation}

The study protocol was approved by hospital ethics committee, and the ethical certificate was obtained. The pre-anesthetic checkup was done 1 day prior to the surgery. Patients were evaluated for any systemic diseases and laboratory investigations were recorded. The procedure of
SAB was explained to the patients and written informed consent in the local language was obtained.

\section{Method}

After meeting inclusion criteria, 60 patients were randomly divided into two groups, 30 each based on computergenerated randomization table.

Group L: Patients received injection levo-bupivacaine, $3 \mathrm{ml}$ $(0.5 \%)$ i.v. with injection. fentanyl, $0.5 \mathrm{ml}(25 \mu \mathrm{g})$ i.v. The mixture was prepared freshly at the time of the procedure, by principle investigator.

Group R: Patients received injection ropivacaine, $3 \mathrm{ml}$ $(0.75 \%)$ i.v. with injection fentanyl, $0.5 \mathrm{ml}(25 \mu \mathrm{g})$ i.v. The mixture was prepared freshly at the time of the procedure, by principle investigator.

\section{Procedure}

After shifting patients to an operating room, i.v. access was obtained on the forearm with No.18G. All subjects were premedicated with injection ranitidine, $50 \mathrm{mg}$ i.v., injection ondansetron, $4 \mathrm{mg}$ i.v. $15 \mathrm{mins}$ before scheduled operative time. All subjects were preloaded with $10 \mathrm{ml} / \mathrm{kg}$ of ringer lactate solution over 10 mins. Baseline hemodynamic parameters were noted after applying standard monitors (pulse oximetry), non-invasive BP and ECG leads. Based on the group the patient belonged to, study drug was injected intrathecally with 23 gauge Quincke needle at the third and fourth lumbar interspaces or second and third lumbar interspaces in sitting/lateral position. Strict aseptic precautions were taken. Injection levo-bupivacaine, $3 \mathrm{ml}$ $(0.5 \%)$ i.v. with $(25 \mu \mathrm{g})$ of injection fentany, $10.5 \mathrm{ml}$ $(25 \mu \mathrm{g})$ or injection ropivacaine, $3 \mathrm{ml}(0.75 \%)$ i.v. with injection fentanyl $0.5 \mathrm{ml}(25 \mu \mathrm{g})$ i.v. was prepared. The patient received $3.5 \mathrm{ml}$ of the either preparation according to randomization. The anesthetic solution was injected over 10-15 sec, after aspiration of clear CSF. Immediately after spinal block subjects were placed in supine position.

Hemodynamic parameters, sensory and motor blockade were assessed at $0,5,10,15,30,45,60,90$, and 120 mins following block. Thereafter, observation was continued at 30 mins intervals until the motor block regressed completely as defined by modified Bromage score.

\section{Parameters evaluated}

1. Duration of sensory block: Defined as the time from intrathecal injection to regression of pinprick sensation to T10 level

2. Degree of motor block: Defined as the time from intrathecal injection to the regression of motor block to Bromage score 0

- 0 - Full movement 
Table 1: Onset-duration of sensory and motor block.

\begin{tabular}{|lccc|}
\hline Parameter & L-bupivacaine & Bupivacaine & Ropivacaine \\
\hline Onset of sensory block (mins) & $8-8.2$ & $6.4-14$ & $10-25$ \\
\hline Duration-sensory block (mins) & $373-451$ & $341-428$ & $102-252$ \\
\hline Onset of motor block (mins) & $17-25$ & $12.5-17.5$ & $33-60$ \\
\hline Duration-motor block (mins) & $195-241$ & $189-265$ & $150-30$ \\
\hline
\end{tabular}

- 1 - Inability to raise extended leg can bend knee

- 2 - Inability to bend the knee but can flex ankle

- 3- No movements.

\section{Hemodynamic parameters}

HR, systolic BP, diastolic BP, mean arterial pressure were assessed every 5 mins until 30 mins, then every 30 mins until the end of study period. The segmental level of sensory block to pinprick was assessed on both sides. The surgery was allowed to start once sensory block had reached at least T10 dermatome. The general anesthesia was induced when the case was labeled as failure. A fall of systolic BP $<20 \%$ of baseline was considered as hypotension and was treated with i.v. bolus of mephentermine, $6 \mathrm{mg}$ and ringer lactate solution as required. HR of $<50$ beats/mins was considered as bradycardia and was treated with injection atropine, $0.6 \mathrm{mg}$, i.v. The end of the study period was defined as the time at which the sensory block had regressed below the T10 dermatome or at which the Bromage score was 0 , whichever occurred later. Time from intrathecal injection to first micturition was noted. Subject's readiness to be discharged/street fitness was assessed and was followed up if required.

\section{Statistical analysis}

Statistical analysis was done using SPSS software 16.0. Data obtained is tabulated in the excel sheet analyzed. Chi-square test for proportion and t-test for quantitative data. Block characteristics were compared using Mann-Whitney U-test.

\section{RESULTS}

This study was conducted over a period of 30-month. 60 patients belonging to ASA physical status I and II were randomly divided into two groups of 30 each based on computer-generated randomization table.

Group L: Patients received $3 \mathrm{ml}$ injection $0.5 \% \mathrm{~L}$-bupivacaine with $0.5 \mathrm{ml}$ of injection fentanyl $50 \mu \mathrm{g} / \mathrm{ml}$. The mixture was prepared freshly at the time of the procedure, by the principal investigator.

Group R: Patients received $3 \mathrm{ml}$ injection $0.75 \%$ ropivacaine with $0.5 \mathrm{ml}$ of injection fentanyl $50 \mu \mathrm{g} / \mathrm{ml}$. The mixture was prepared freshly at the time of the procedure, by the principal investigator.
Table 2: Demographic characteristics.

\begin{tabular}{|lccc|}
\hline \multirow{2}{*}{ Characteristics } & \multicolumn{2}{c}{$\mathbf{n = 6 0}$} & p value \\
\cline { 2 - 4 } & Group R & Group L & \\
\hline Age (years) & $40.8 \pm 11.7$ & $39.79 \pm 10.98$ & $0.85 \mathrm{NS}$ \\
\hline Weight $(\mathrm{kg})$ & $62.93 \pm 6.38$ & $62.93 \pm 6.38$ & $0.06 \mathrm{NS}$ \\
\hline Height $(\mathrm{cm})$ & $163.91 \pm 6.01$ & $162.87 \pm 5.98$ & $0.34 \mathrm{NS}$ \\
\hline BMI & $23.3 \pm 1.23$ & $22.9 \pm 1.34$ & $0.07 \mathrm{NS}$ \\
\hline $\begin{array}{l}\text { Level of needle } \\
\text { insertion } \\
\text { (L2-L3)/(L3-L4) }\end{array}$ & $12 / 18$ & $10 / 16$ & $0.42 \mathrm{NS}$ \\
\hline ASA Status I/II & $46 / 14$ & & \\
\hline
\end{tabular}

NS: Non-significant, student's t-test applied, both the groups are comparable with respect to age, sex, height, weight, BMI, level of SAB, ASA score ( $p>0.05)$. BMI: Body mass index, ASA: American Society of Anesthesiologist, SAB: Subarachnoid block

Data obtained were analyzed, and final results are shown in Tables 1-5.

The mean time for onset of motor block (Bromage 3 ) was $13.9 \pm 2.9$ mins for Group $\mathrm{R}$ and $12.9 \pm 3.9$ mins for Group L with $\mathrm{p}=0.16$ which was clinically and statistically not significant. The time taken for two segment regression of sensory block was $95.98 \pm 8.2$ mins in Group $\mathrm{R}$ and $98.04 \pm 8.5$ mins in the Group L. $p=0.22$ and statistically not significant.

In this study, there was the statistical significant difference in duration for regression of sensory block to T10 with Group R $119.0 \pm 24.0$ mins compared to Group L $153 \pm 20.4$ mins $(p<0.001)$. In this study, there was a statistically significant difference in time for regression of motor block to Bromage score 0 with Group R $144.5 \pm 26.1$ mins as compared with Group L $181.0 \pm 21.3$ mins $(\mathrm{p}<0.001)$. In this study, the Bromage score of 3 was achieved in $100 \%$ of Group L and $80 \%$ of Group R. In this study, there was the statistical significant difference in time to first micturition with Group $\mathrm{R}$ $245 \pm 40.9$ mins to Group L $290 \pm 47.6$ mins ( $<<0.001$ ).

In both groups fall in systolic BP was recorded after the institution of spinal anesthesia. Maximum fall in systolic BP among both groups was seen between 10 and 25 mins. The magnitude of fall in systolic BPs was similar in both groups, and it was not clinically or statistically significant.

No cases of allergy or respiratory depression were reported. There was no clinical or statistical significance in the incidence of side effects in both groups. 
Table 3: Time to onset of sensory - motor blockade.

\begin{tabular}{|lccc|}
\hline Parameter & Group L & Group R & p value \\
\hline Onset of sensory block & $7.98 \pm 2.2$ & $8.28 \pm 2.2$ & 0.49 \\
\hline Onset of motor block & $12.9 \pm 3.9$ & $13.9 \pm 2.9$ & 0.16 \\
\hline $\begin{array}{l}\text { Time for two segment } \\
\text { regression }\end{array}$ & $95.98 \pm 8.2$ & $98.04 \pm 8.5$ & $0.22 \mathrm{NS}$ \\
\hline
\end{tabular}

Values are expressed as mean $\pm \mathrm{SD}$ students unpaired t-test. The mean time for onset of sensory block was $8.28 \pm 2.2$ mins for Group R and 7.98 \pm 2.2 mins for Group L with $\mathrm{p}=0.49$ which was clinically and statistically not significant. SD: Standard deviation

Table 4: Block characteristics.

\begin{tabular}{|lccc|}
\hline Parameter & \multicolumn{2}{c}{$\mathbf{n = 6 0}$} & p value \\
\cline { 2 - 4 } & Group R & Group L & \\
\hline $\begin{array}{l}\text { Duration of } \\
\text { sensory block }\end{array}$ & $119.0 \pm 24.4$ & $153 \pm 20.4$ & $<0.001 \mathrm{HS}$ \\
\hline $\begin{array}{l}\text { Duration of } \\
\text { motor block }\end{array}$ & $144.5 \pm 26.1$ & $181.0 \pm 21.3$ & $<0.001 \mathrm{HS}$ \\
\hline $\begin{array}{l}\text { Degree of motor } \\
\text { block* (Grade 3) }\end{array}$ & $80 \%$ & $100 \%$ & $<0.001 \mathrm{HS}$ \\
\hline $\begin{array}{l}\text { Time to first } \\
\text { micturition }\end{array}$ & $245 \pm 40.9$ & $290 \pm 47.6$ & $<0.001 \mathrm{HS}$ \\
\hline HS: Highly significant, student's t-test applied & \\
\hline
\end{tabular}

Table 5: Comparison of side effects between the two groups.

\begin{tabular}{|lcc|}
\hline Side effects & \multicolumn{2}{c|}{ n (\%) } \\
\hline Nausea & Group R & Group L \\
\hline Vomiting & $2(4)$ & $3(6)$ \\
\hline Hypotension & $1(2)$ & $2(4)$ \\
\hline Bradycardia & $2(4)$ & $3(6)$ \\
\hline Respiratory depression & 0 & $2(4)$ \\
\hline
\end{tabular}

\section{DISCUSSION}

\section{Demographic profile across the group}

In this study, the majority of patients were middle-aged in both the groups. The mean height, mean weight, and mean BMI in either group were also identical. The types of surgeries performed were also identical in both the groups. These parameters were kept identical in both the groups to avoid variations in intraoperative and post-operative outcome of patients.

\section{Onset of peak sensory block}

Onset of sensory block at the highest dermatomal level using pinprick method was noted in both groups. The mean time for onset of peak sensory block in Group R was $8.28 \pm 2.2$ mins and in Group L was $7.98 \pm 2.2$ mins, with $p=0.49$, which was statistically not significant.
This observation was comparable to the study done by Malinowski et al., who compared intrathecal isobaric ropivacaine, $15 \mathrm{mg}$ and isobaric bupivacaine, $10 \mathrm{mg}$ for transurethral resection of bladder or prostrate. It was found that the onset of sensory blockade was similar and was $13 \pm 8$ mins for ropivacaine group compared to $11 \pm 7$ mins in the bupivacaine group. This was statistically not significant. ${ }^{4}$

In another study done by Kallio et al., 90 patients undergoing ambulatory lower extremity surgery received either $2 \mathrm{ml}$ of $0.75 \%$ ropivacaine or $2 \mathrm{ml}$ of $0.5 \%$ bupivacaine. It was found that median onset of sensory block was similar in both groups and was 10 mins which is similar to the observation in this study. ${ }^{5}$

\section{Highest level of sensory block}

Malinowski et al., in their study, noted a similar trend for maximum cephalic spread and variation of the sensory block between the intrathecal ropivacaine $(15 \mathrm{mg})$ group and bupivacaine $(10 \mathrm{mg})$ group for transurethral resection of bladder or prostrate. In this study, the highest level of sensory blockade achieved was similar in both groups. The highest level of block achieved in Group R was T6 in $\mathrm{n}=2(4 \%)$ patients. The highest level of block achieved in Group $L$ was also $\mathrm{T} 6$ in $n=5(10 \%)$ patients. $56 \%$ of patients of Group R achieved a sensory block up to T10, whereas $50 \%$ of patients of Group L achieved a maximum sensory block up to the level of T10. These findings were clinically and statistically not significant.

\section{Time for two segment regression}

Gautier et al., in their study, noted the time for two segment regression was similar between the two groups and was $89 \pm 33$ mins in the ropivacaine group and was $98 \pm 30$ mins in the levo-bupivacaine group when administered intrathecally. This correlates with the finding in this study. In this study, the time taken for two segment regression of sensory block was $95.98 \pm 8.2$ mins in the Group $\mathrm{R}$ and $98.04 \pm 8.5$ mins in the Group L. $\mathrm{p}=0.22$ and statistically not significant. Malinowski et al., in their study also noted similar duration for two segment regression between the two groups which correlates with this study. ${ }^{6}$

\section{Duration of sensory block (regression to s1)}

Chung et al. noted that time of regression of block to $\mathrm{S} 1$ was longer (188.56 $\pm 28.2 \mathrm{mins})$ in intrathecal bupivacaine group when compared to ropivacaine group (162.56 $\pm 20.2 \mathrm{mins})$. In this study, there was the statistical significant difference in duration for regression of sensory block to T10 with Group R $119.0 \pm 24.0$ mins compared to Group L $153 \pm 20.4$ mins $(\mathrm{p}<0.001)$. Ropivacaine group was associated with the shorter duration of sensory block compared to levobupivacaine group. ${ }^{?}$ 


\section{Onset of complete motor block}

Malinovsky et al. found that onset of motor blockade was similar in the two groups receiving ropivacaine and bupivacaine intrathecally for transurethral resection of bladder or prostrate. Kallio et al. and McNamee et al. ${ }^{8}$ also found similar time to onset of the complete motor block. This correlates with the results obtained in this study, which found similar time to onset of the maximum motor blockade. In this study, the mean time for onset of motor block (Bromage 3) was $13.9 \pm 2.9$ mins for Group $\mathrm{R}$ and $12.9 \pm 3.9$ mins for Group L with $\mathrm{p}=0.16$, which was clinically and statistically not significant.

\section{Degree of motor block}

Chung et al. observed complete motor block in all patients receiving either bupivacaine or ropivacaine intrathecally for cesarean section. Boztug et al. ${ }^{9}$ observed complete motor blockade in $88 \%$ of patients receiving ropivacaine and $100 \%$ patients receiving bupivacaine when administered for knee arthroscopy.

In this study, the Bromage score of 3 was achieved in 100\% of Group L and $80 \%$ of Group R. ropivacaine group is associated with less dense motor block than levo-bupivacaine group.

\section{Duration of motor block}

McNamee et al. noted that duration of motor block was significantly shorter in the ropivacaine group $(2.1 \mathrm{hrs})$ as compared to the bupivacaine group ( $3.9 \mathrm{hrs})$. Kallio et al. also noted the duration of motor block was significantly shorter with ropivacaine (150 mins) as compared to bupivacaine (210 mins). Mantaouvalou et al. noted that the duration of motor block was significantly shorter in the ropivacaine group also when compared to the bupivacaine group. This correlates with the findings in this study where the time to recovery of the complete motor block (Grade 3 to Grade 0) was $144.5 \pm 26.1 \mathrm{mins}$ in the ropivacaine group and $181.0 \pm 21.3$ mins in the levo-bupivacaine group. This was statistically highly significant $(\mathrm{p}<0.001)$. The findings in this study are in affirmation with that of Chung et al.

In 2007, Camorcia et al. conducted a study, to determine the median effective dose (ED50) for a motor block of intrathecal ropivacaine, levo-bupivacaine, and bupivacaine and to define their motor-blocking potency ratios. There is a clinical profile of potency for motor block for the pipecolylxylidines when administered spinally: low, intermediate, and high for ropivacaine, levo-bupivacaine, and bupivacaine, respectively. ${ }^{10}$

In 2008, Luck compared intrathecal hyperbaric solutions of racemic bupivacaine, levo-bupivacaine, and ropivacaine. Hyperbaric ropivacaine provides reliable spinal anesthesia of shorter duration than bupivacaine or levo-bupivacaine, both of which are clinically indistinguishable. The recovery profile of ropivacaine may be useful where prompt mobilization is required. The above studies correlate with the findings in this study where ropivacaine is associated with less duration of motor block and less intense degree of motor blockade causing early mobilization of patients. ${ }^{11}$

In 2005, Kallio et al. studied spinal hyperbaric ropivacaine - fentanyl for day surgery. Faster mobilization but equal onset and duration of analgesia were achieved with intrathecal hyperbaric ropivacaine $10 \mathrm{mg}$ plus fentanyl $20 \mu \mathrm{g}$ as compared with hyperbaric ropivacaine $15 \mathrm{mg} .{ }^{12}$

In 2005, Yegin et al. studied intrathecal fentanyl added to hyperbaric ropivacaine for transurethral resection of the prostate. Regression to L1 was significantly prolonged in the fentanyl group. Addition of fentanyl $25 \mu \mathrm{g}$ to hyperbaric ropivacaine $18 \mathrm{mg}$ for spinal anesthesia in patients undergoing transurethral resection of the prostate TURP may significantly improve the quality and prolong the duration of analgesia, without causing a substantial increase in the frequency of major side-effects. ${ }^{13}$

In 2005, Lee et al. studied levo-bupivacaine and fentanyl for spinal anesthesia: a randomized trial concludes that $2.3 \mathrm{ml}$ of $0.5 \%$ levo-bupivacaine with fentanyl $15 \mu$ is as effective as $2.6 \mathrm{ml}$ of $0.5 \%$ levo-bupivacaine alone in spinal anesthesia for urological surgery. Further studies may be directed to find the optimal combination of levo-bupivacaine and opioid with maximal hemodynamic stability and least motor block. ${ }^{14}$

In 2014, Chaudhary et al. studied the efficacy of spinal ropivacaine versus ropivacaine with fentanyl in transurethral resection operations. The addition of fentanyl $(10 \mu \mathrm{g})$ to ropivacaine $(0.75 \% 2 \mathrm{ml}$ vs. $1.8 \mathrm{ml})$ may offer the advantage of shorter duration of complete motor block, hemodynamic stability, and without any increase in the frequency of major side effects. ${ }^{15}$

In 2013, Akan et al. compared levo-bupivacaine alone and in combination with fentanyl and sufentanil in patients undergoing transurethral resection of the prostate. This study showed that combining lower dose levo-bupivacaine with fentanyl and sufentanil provides faster onset of sensorial block, lower frequency and shorter duration of motor block, and longer analgesia time in TURP under spinal anesthesia. ${ }^{16}$

In 2011, Taspinar et al. studied low-dose ropivacaine ( $5 \mathrm{mg}$ of $0.5 \%$ ) or levo-bupivacaine $(3.75 \mathrm{mg}$ of $0.75 \%$ ) with fentanyl $25 \mu \mathrm{g}$, walking spinal anesthesia in ambulatory inguinal herniorrhaphy and concluded that levo-bupivacaine may be an alternative local anesthetic for walking spinal anesthesia as it provides minimum motor block and a long duration of post-operative analgesia, even if its use is not associated with a shorter home discharge time. ${ }^{17}$ 
In 2011, Akcaboy et al. compared low dose levo-bupivacaine $0.5 \%$ with fentanyl in spinal anesthesia for transurethral resection of prostate surgery and concluded that for transurethral prostate surgery $5 \mathrm{mg}$ levo-bupivacaine with $25 \mu \mathrm{g}$ fentanyl can provide stable hemodynamic profile, patient and surgeon satisfaction and effective sensorial blockade with less motor blockade in spinal anesthesia; so, it could be used at low doses as a good alternative to bupivacaine. $^{18}$

In 2010, Panni et al. studied minimum effective dose of spinal ropivacaine with and without fentanyl for postpartum tubal ligation and concluded that ropivacaine $22 \mathrm{mg}$ with or without fentanyl $10 \mu \mathrm{g}$ may be the ideal spinal anesthetic for postpartum tubal ligation due to its medium duration of action, low incidence of side-effects and possibly reduced post anesthetic care unit stay. ${ }^{19}$

In 2010, Erturk et al. compared $12 \mathrm{mg}$ ropivacaine and $8 \mathrm{mg}$ bupivacaine, both with $20 \mu \mathrm{g}$ fentanyl, in spinal anesthesia for major orthopedic surgery in geriatric patients and concluded that they provide sufficient motor and sensory block for major orthopedic surgery in geriatric patients. However, ropivacaine caused less motor block and hemodynamic side effects than bupivacaine during the procedure. ${ }^{20}$

In 2009, Koltka et al. compared equipotent doses of ropivacaine-fentanyl and bupivacaine-fentanyl in spinal anesthesia for lower abdominal surgery and concluded that plain ropivacaine $19.5 \mathrm{mg}$ plus fentanyl $20 \mu \mathrm{g}$ is associated with a lower level of sensory block and a shorter duration of motor block when compared to bupivacaine $13 \mathrm{mg}$ plus fentanyl $20 \mu \mathrm{g}$ for spinal anesthesia in lower abdominal surgery. ${ }^{21}$

The above studies correlate with the findings in this study where ropivacaine and levo-bupivacaine is associated with less duration of motor block ropivacaine $>$ levo-bupivacaine $>$ bupivacaine and less intense degree of motor blockade with ropivacaine but not with levo-bupivacaine, causing early mobilization of patients with prolonged duration of analgesia due to the addition of fentanyl. In this study, there was the statistical significant difference in time to first micturition with Group R $245 \pm 40.9$ mins to Group L $290 \pm 47.6$ mins $(\mathrm{p}<0.001)$.

\section{Quality of intra operative analgesia}

The quality of intra operative analgesia was satisfactory in most of the patients in both groups, and the anesthesia was well-accepted by most of the patients in both groups.

\section{Hemodynamic parameters}

In this study, hypotension occurred in $4 \%$ of the cases in the ropivacaine group and $6 \%$ of the cases in levo-bupivacaine group and was easily managed by ephedrine boluses, bradycardia was seen in none of the cases in ropivacaine group and 45 of the cases in levo-bupivacaine group. The hemodynamic parameters including pulse rate, systolic, and diastolic BPs were comparable between both groups, and no significant hemodynamic alteration was seen in the two groups. This correlates with the study done by Koltka et al. ${ }^{21}$

\section{Side effects}

Incidence of nausea and vomiting were comparable between both the groups in this study. No other side effects were noted in the study.

\section{CONCLUSION}

This study reveals that the intrathecal $3.5 \mathrm{ml}$ of $0.75 \%$ ropivacaine with fentanyl $25 \mu \mathrm{g}$ provides adequate anesthesia for lower abdominal and lower limb surgeries. Ropivacaine achieves a lesser duration of sensory and motor blockade, lesser degree of the motor blockade as compared with levo-bupivacaine. With the quality and duration of block achieved with ropivacaine, it can be justified to use it for lower abdominal and lower limb surgeries or surgeries which are short duration ambulatory surgeries and not requiring intense motor blockade. Furthermore, fentanyl as an adjuvant to both ropivacaine and levo-bupivacaine enhances the duration of the sensory block.

Hence, ropivacaine with fentanyl in spinal anesthesia for lower abdominal and lower limb surgeries is a better alternative compared to levo-bupivacaine with fentanyl favoring day care ambulatory surgeries.

\section{ACKNOWLEDGMENTS}

We are thankful to the Head of the Department and Staff of the, Department of Anaesthesiology, Dr. Pinnamaneni Siddhartha Institute of Medical Sciences and Research Foundation, Chinnaoutpalli, Andhra Pradesh, India, and Head of the Department of Pharmacology, Siddhartha Medical College, Vijayawada, Andhra Pradesh, India, for their valuable suggestions and support.

\section{Funding: No funding sources}

Conflict of interest: None declared

Ethical approval: The study was approved by the Institutional Ethics Committee

\section{REFERENCES}

1. Leone S, Di Cianni S, Casati A, Fanelli G. Pharmacology, toxicology, and clinical use of new long acting local anesthetics, ropivacaine and levobupivacaine. Acta Biomed. 2008;79(2):92-105.

2. Vanna O, Chumsang L, Thongmee S. Levobupivacaine and bupivacaine in spinal anesthesia for transurethral endoscopic surgery. J Med Assoc Thai. 2006;89(8):1133-9. 
3. Turkmen A, Moralar DG, Ali A, Altan A. Comparison of the anesthetic effects of intrathecal levobupivacaine + fentanyl and bupivacaine + fentanyl during caesarean section. Middle East J Anaesthesiol. 2012;21(4):577-82.

4. Malinovsky JM, Charles F, Kick O, Lepage JY, Malinge M, Cozian A, et al. Intrathecal anesthesia: ropivacaine versus bupivacaine. Anesth Analg. 2000;91(6):1457-60.

5. Kallio H, Snäll EV, Kero MP, Rosenberg PH. A comparison of intrathecal plain solutions containing ropivacaine 20 or $15 \mathrm{mg}$ versus bupivacaine $10 \mathrm{mg}$. Anesth Analg. 2004;99(3):713-7.

6. Gautier E, De Kock M, Van Steenberge A. comparison between intrathecal bupivacaine and ropivacaine for knee arthroscopy. Anaesthesiology. 1999;91(5):1239-45.

7. Chung CJ, Choi SR, Yeo KH, Park HS, Lee SI, Chin YJ. Hyperbaric spinal ropivacaine for cesarean delivery: a comparison to hyperbaric bupivacaine. Anesth Analg. 2001;93(1):157-61.

8. McNamee DA, Parks L, McClelland AM, Scott S, Milligan KR, Ahlén K, et al. Intrathecal ropivacaine for total hip arthroplasty: double-blind comparative study with isobaric $7.5 \mathrm{mg} \mathrm{ml}(-1)$ and $10 \mathrm{mg} \mathrm{ml}(-1)$ solutions. Br J Anaesth. 2001;87(5):743-7.

9. Boztug N, Bigat Z, Karsli B, Saykal N, Ertok E. Comparison of ropivacaine and bupivacaine for intrathecal anesthesia during outpatient arthroscopic surgery. J Clin Anesth. 2006;18:521-52.

10. Camorcia M, Capogna G, Berritta C, Columb MO. The relative potencies for motor block after intrathecal ropivacaine, levobupivacaine, and bupivacaine. Anesth Analg. 2007;104(4):904-7.

11. Luck JF, Fettes PD, Wildsmith JA. Spinal anaesthesia for elective surgery: a comparison of hyperbaric solutions of racemic bupivacaine, levobupivacaine, and ropivacaine. $\mathrm{Br}$ J Anaesth. 2008;101(5):705-10.

12. Kallio H, Snäll EV, Suvanto SJ, Tuomas CA, Iivonen MK, Pokki JP, et al. Spinal hyperbaric ropivacaine-fentanyl for day-surgery. Reg Anesth Pain Med. 2005;30(1):48-54.

13. Yegin A, Sanli S, Hadimioglu N, Akbas M, Karsli B. Intrathecal fentanyl added to hyperbaric ropivacaine for transurethral resection of the prostate. Acta Anaesthesiol Scand. 2005;49(3):401-5.
14. Lee YY, Muchhal K, Chan CK, Cheung AS. Levobupivacaine and fentanyl for spinal anaesthesia: a randomized trial. Eur J Anaesthesiol. 2005;22(12):899-903.

15. Chaudhary A, Bogra J, Singh PK, Saxena S, Chandra G, Verma R. Efficacy of spinal ropivacaine versus ropivacaine with fentanyl in transurethral resection operations. Saudi J Anaesth. 2014;8(1):88-91.

16. Akan B, Yagan O, Bilal B, Erdem D, Gogus N. Comparison of levobupivacaine alone and in combination with fentanyl and sufentanil in patients undergoing transurethral resection of the prostate. J Res Med Sci. 2013;18(5):378-82.

17. Taspinar V, Sahin A, Donmez NF, Pala Y, Selcuk A, Ozcan M, et al. Low-dose ropivacaine or levobupivacaine walking spinal anesthesia in ambulatory inguinal herniorrhaphy. J Anesth. 2011;25(2):219-24.

18. Akcaboy EY, Akcaboy ZN, Gogus N. Low dose levobupivacaine $0.5 \%$ with fentanyl in spinal anaesthesia for transurethral resection of prostate surgery. J Res Med Sci. 2011;16(1):68-73.

19. Panni MK, George RB, Allen TK, Olufolabi AJ. Minimum effective dose of spinal ropivacaine with and without fentanyl for postpartum tubal ligation. Int J Obstet Anesth. 2010;19(4):390-4.

20. Erturk E, Tutuncu C, Eroglu A, Gokben M. Clinical comparison of $12 \mathrm{mg}$ ropivacaine and $8 \mathrm{mg}$ bupivacaine, both with 20 microg fentanyl, in spinal anaesthesia for major orthopaedic surgery in geriatric patients. Med Princ Pract. 2010;19(2):142-7.

21. Koltka K, Uludag E, Senturk M, Yavru A, Karadeniz M, Sengul T, et al. Comparison of equipotent doses of ropivacaine-fentanyl and bupivacaine-fentanyl in spinal anaesthesia for lower abdominal surgery. Anaesth Intensive Care. 2009;37(6):923-8.

Cite this article as: Vampugalla PS, Vundi VR,

Perumallapalli KS, Kumar CV, Kambar C, Mahalakshmi M, Pisipati RS. A comparative study of intrathecal ropivacaine with fentanyl and L-bupivacaine with fentanyl in lower abdominal and lower limb surgeries. Int J Basic Clin Pharmacol 2015;4:1147-55. 